\title{
Missionaries Experience Mental and Spiritual Health Gains While Caring for the Poor in Residential Facilities in J amaica
}

\author{
Thaxter Nesbeth KA ${ }^{1 *}$ and Dayandayan J $\mathbf{P}^{2}$ \\ ${ }^{1}$ Department of Basic Medical Sciences, University of the \\ West Indies, Mona, J amaica \\ ${ }^{2}$ Missionaries of the Poor, 87-90 Hanover Street, \\ Kingston, J amaica \\ *Corresponding author: Thaxter Nesbeth KA, \\ Department of Basic Medical Sciences, Physiology \\ Section, University of the West Indies, Mona, Kingston 7, \\ Jamaica
}

Received: April 25, 2017; Accepted: May 17, 2017;

Published: May 24, 2017

\begin{abstract}
Objective: Psychological and spiritual caregiving gains in cross-cultural missionaries providing invaluable formal, unpaid, full time care at residential facilities in a remote, inner-city island setting were investigated.

Method: One hundred and ten (110) Missionary caregivers of over 500 mentally and physically challenged and terminally ill children and adults in residential mission facilities completed a validated 10-item questionnaire, investigating positive aspects of caregiving and spiritual gain.
\end{abstract}

Results: ANOVA on mean frequencies demonstrated significant gains in self-affirmation $(p<0.001)$, outlook on life $(p<0.001)$, and a strengthened relationship with God $(p<0.001)$.

Conclusion: Psychological and spiritual gains of missionaries providing vital care at residential facilities highlighted positive aspects of caregiving.

Keywords: Positive aspects of caregiving; Missionary; Residential home; Spiritual health; Mental health

\section{Introduction}

A caregiver enables another to achieve relative wellness, in the short, medium or long term. The psychological, physical and spiritual demands of caregiving make the health-related quality of life of the caregiver vulnerable to decline. Maintenance of efforts to meet the needs of the care recipient presents an unending challenge [1]. Previously, Maslach and Jackson [2] directed attention to caregiver research focused on burnout - defined as a syndrome of emotional exhaustion and cynicism that occurs frequently among individuals who interface with people at work [3]. The discovery and management of burnout was aimed at protecting the caregiver but the resultant negative ethos in appropriately skewed thinking toward unfavorable outcomes.

This study is built on the 'strength-based perspective' which proposes that the abilities, expertise, hopes, values and potential of each person should be emphasized, regardless of the stressful nature of the situation around them [4]. This perspective is not naive in its approach to providing insight into the caregiving experience. On the contrary, negative events are acknowledged as one part of the experience of life for each individual, and strengths are brought into focus as personal and sociocultural conditions and coping strategies are explored [5].

Health care, and the establishment and maintenance of institutions to care for the sick have been a focal point for Christian missionaries since the middle ages. There are an estimated 400,000 Christian missionaries working cross culturally around the world [6]. Such are the missionaries in this study, who maintain priority focus on service to the marginalized and destitute. At residential mission facilities, they provide full time care for abandoned, terminally ill, physically and mentally disabled, homeless destitute men, women and children. These shelters provide permanent residence for over 500 persons, representing an inestimable economic and social contribution to Jamaica, a developing country. The missionaries (locally known as 'Brothers') conduct all hygiene, nutrition, mobility, toileting, home medical daily living care for all of the residents. It is an intense, unremitting, daily caregiving role.

The study aimed to identify positive aspects of caregiving (PAC) and spiritual gains for these cross-cultural missionaries.

\section{Design}

This study was a quantitative, descriptive, cross-sectional census of a single group of 110 formal, unpaid missionary caregivers at residential facilities.

\section{Methods}

Ethical approval was obtained from the University of the West Indies Faculty of Medical Sciences Ethics committee prior to administration of the survey. Brothers included in the sample were professed missionaries for at least 3 years, had lived on the island for at least 2 years and were providing full-time care to residents at one of the 6 residential facilities for at least 2 years.

Demographic data collected were age, country of birth and number of years working with residents in the homes. The internationally accepted nine-item Positive Aspects of Caregiving (PAC) tool [7] was used in its entirety, with permission. It was previously validated by those authors with an appropriate culturally and ethnically diverse sample. A $10^{\text {th }}$ item related to spiritual strengthening was included, 
after face validity was obtained from 10 spiritual experts and leaders in the organization.

Each participant was asked to respond to the list of questions below using the 5-point Likert scale consisting of (i) agree a little, (ii) agree a lot, (iii) disagree a little, (iv) disagree a lot or(v) unsure:

Providing care for residents has

(1) made me feel more useful

(2) made me feel good about myself

(3) made me feel more needed

(4) made me feel appreciated

(5) made me feel important

(6) made me feel strong and confident

(7) enabled me to appreciate life more

(8) enabled me to develop a more positive attitude toward life

(9) strengthened my relationship with others

(10) strengthened my relationship with God.

Test-retest reliability was executed and obtained prior to the main interview session. Informed consent was provided, and then the self-administered questionnaire was filled out individually and confidentially, during a single designated study time, at the monastery. There were no assigned identifiers. Completed forms were secured, and confidentiality maintained, until after analysis, when the forms were destroyed.

\section{Data Analysis}

The Statistical Package for the Social Sciences (SPSS version 22.0) was used to calculate mean frequencies for demographic data and each question, compared thereafter using ANOVA. The nine PAC questions were assigned to the factor loading identified in the original factor analysis of outcomes of the tool: questions 1-6 were analysed together as reflecting 'Self-affirmation', and questions 7-9 reflected 'Positive outlook on life'[7]. The question investigating 'strengthened relationship with God' was analysed on its own.

\section{Results}

There was a $100 \%$ response rate for the survey. The majority (98\%) of missionaries hailed from the continents of Asia and Africa $(\mathrm{p}<0.001)$, and the remaining $2 \%$ originated from the West Indies. Significantly, the majority (76\%) were in the younger (16-30y) of two age brackets $(p<0.001)$. The significant majority $(98 \%)$ of respondents had 3-15 years of membership in missionaries of the Poor, while only $2 \%$ of respondents had 16 years of MOP experience.

ANOVA on mean frequencies showed that the significant majority of missionaries reported positives in self-affirmation $(\mathrm{p}<0.001)$ and improved outlook on life $(\mathrm{p}<0.001)$ through caregiving. Also, the significant majority of missionaries answered that caregiving has strengthened their relationship with God $(\mathrm{p}<0.001)$.

\section{Discussion}

The results of this study provide meaningful diversity to the body of caregiver research. They show prominent psychological and spiritual gains for missionary caregivers providing full time, formal, unpaid care to the poor on the lowest urban fringes of a small island city. It is not intuitive; however, that this population should experience health gains from their work. They are, on average, young: $98 \%$ were adolescents and youth, (in the 16-30 age range). This could have heightened vulnerability to psychosocial stressors. They are also a long way from home, and perform menial and often unpleasant caregiving tasks daily. They communicate in their second language, frequently in blistering humid conditions; and face unpredictable cultural, social and physical challenges. Yet, the results provide indicators of improved psychological and spiritual health.

Caregiving and health have to be examined with regard to the context [1]. Those authors assert that the caregiving burden may be moderated by the social setting and motives to provide care. The missionaries in this study are not impermeable to fear, guilt, regret, fatigue or frustration. They do, however, operate within a clearly defined social and organizational structure. There is also universally available formal and informal social, psychological and spiritual support within the missionary organization.

Strand and workers [6] emphasised the vulnerability of cross cultural missionaries to mental health challenges. They cited the high incidence of depressive and adjustment disorders among this population, and the ensuing decrease in their health-related quality of life. Our population showed good evidence of coping - defined by Malhotra and Thapa [8] as the set of concrete responses to a stressful situation or event that are intended to resolve the problem, or reduce distress. The missionary life has an intrinsic component of religious coping, which may involve such activities as prayer, pastoral care, religious faith and community and congregational support [8]. Those authors cautioned, however, that religious coping may be positive (problems have solutions which are achieved by God and myself) or negative (problems are punishment from God). Positive religious coping embodies the experience of God as director, enabler and supportive partner. Positive religious coping has a notable stressbuffering effect, with more positive caregiver health outcomes [6]. Importantly, positive religious coping was implicit in the universal response of strengthened relationship with God as a result of the caring role, for missionaries in this study.

Exploration of the spirituality of the individual is valuable in clinical practice. The American Academy of Family Physicians recommends that the Spiritual Assessment to be performed at every clinical encounter. Of relevance here is the 'Open-Invite' mnemonic for the recommended approach to commencing conversation regarding spirituality and religious coping. The practitioner is invited to 'open' the door to conversations about religion, and then to 'invite' the patient to discuss spiritual needs, and practices. This approach is likely to strengthen the practitioner-patient relationship, while offering opportunities for personal renewal, resiliency and growth $[9,10]$.

The strength-based theory of caregiver analysis offers a vital platform for the development of meaningful, effective therapeutic strategies and interventions for family, community, formal, and informal carers. It provides the practitioner with the opportunity to teach the individual to garner long term motivation via a consistent 
emphasis on strengths. This facilitates a process that diminishes focus on burden and strain, and enables a more balanced view of an individual's reality [5].

Focus on the strength-based perspective in the current study is useful as so few interventions have been recorded for caregivers within the religious context. Our work opens the door to strategies that combine focusing on the PAC with exploration of the spirituality and religious foci of the individual, as a way to multiply caregiver gains.

\section{References}

1. Kaschowitz J, Brandt M. Health effects of informal caregiving across Europe A longitudinal approach. Social Science \& Medicine. 2017; 173: 72-80.

2. Maslach C, Jackson SE. The measurement of experienced burnout. Journal of organizational behavior. 1981; 2: 99-113.

3. Peacock S, Forbes D, Markle-Reid M, Hawranik P, Morgan D, Jansen L, et al. The positive aspects of the caregiving journey with dementia: Using a strengths-based perspective to reveal opportunities. Journal of Applied Gerontology. 2010; 29: 640-659.

4. Lou VW, Lau BH, Cheung KS. Positive aspects of caregiving (PAC): Scale validation among Chinese dementia caregivers (CG). Archives of gerontology and geriatrics. 2015; 60: 299-306
5. Walker RV, Powers SM, Bisconti TL. Positive Aspects of the Caregiving Experience: Finding Hope in the Midst of the Storm. Women \& Therapy. 2016; 39: 354-370

6. Strand M, Pinkston L, Chen A, Richardson J. Mental health of cross-cultural healthcare missionaries. J Psych Theo. 2015; 43: 283-293.

7. Tarlow BJ, Wisniewski SR, Belle SH, Rubert M, Ory MG, GallagherThompson D. Positive aspects of caregiving: Contributions of the REACH project to the development of new measures for Alzheimer's caregiving. Research on aging. 2004; 26: 429-453.

8. Malhotra M, Thapa K. Religion and coping with caregiving stress. Int J of Multidisciplinary and Current research. 2015; 3.

9. Saguil A, Phelps K. The spiritual assessment. American family physician. 2012; 86: 546-550

10. Gray RS, Hahn L, Thapsuwan S, Thongcharoen chupong N. Strength and stress: Positive and negative impacts on caregivers for older adults in Thailand. Australasian journal on ageing. 2016; 35: E7-12.
J Fam Med - Volume 4 Issue 4 - 2017

ISSN : 2380-0658 | www.austinpublishing group.com

Thaxter Nesbeth et al. (C) All rights are reserved
Citation: Thaxter Nesbeth KA and Dayandayan JP. Missionaries Experience Mental and Spiritual Health Gains While Caring for the Poor in Residential Facilities in Jamaica. J Fam Med. 2017; 4(4): 1118. 